Jurnal Indonesia Sosial Teknologi: p-ISSN: 2723 - 6609

e-ISSN : 2745-5254

Vol. 2, No. 7 Juli 2021

\title{
ANALISIS OVERALL EQUIPMENT EFFECTIVENESS UNTUK MENINGKATKAN KEEFEKTIFAN PADA MESIN PRESS
}

\author{
Mochamad Irfan \\ Universitas Mercu Buana \\ Email: mochamadirfan011@gmail.com
}

\begin{abstract}
Abstrak
Industri manufaktur khususnya industri otomotif di Indonesia sangat berkembang begitu pesat. Kebijakan suatu perusahaan untuk memenangkan persaingan bisinis sangat dibutuhkannya suatu keefektifan dan effisienan dalam pengelolaan perusahaan. Kebijakan yang di ambil pada PT.XYZ salah satunya adalah meningkatkan kapasitas produksi. Kebijakan ini dilakukan dengan adanya penambahan mesin maupun meningkatan output pada mesin-mesin yang sudah ada. Metode yang digunakan untuk mengukur kinerja mesin pada PT.XYZ salah satunya adalah Overall Equipment Effetiveness (OEE) yang dasari dari Total Productive Maintenance (TPM). Dari hasil perhitungan diperoleh presentase nilai Overall Equipment Effectiveness (OEE) pada bulan Agustus 2019 yaitu sebesar 70\%. Nilai yang diperoleh belum mencukupi standar nilai yang sudah ditetapkan pada hasil nilai OEE yang nilainya sebesar $85 \%$. Bila dilihat pada Diagram Pareto untuk faktor Reduce Speed Loss memiliki total time loss terbanyak dan frekuensi kumulatif terendah dari Six Big Losses yang sangat mempengaruhi hasil nilai OEE yang sudah didapat. PT.XYZ harus memberikan pelatihan kepada operator terhadap maintanence mesin tersebut sehingga performance mesin press dapat meningkat, melalukan inpeksi terhadap die dan membuat penjadwalan terkait dalam pemeriksaan die secara rutin, Membuat tim Inspektor khusus agar dapat melakukan inspeksi secara rutin, dan melalukan penyetokan terhadap suku cadang yang krusial
\end{abstract}

Kata kunci: overall equipment effetiveness (OEE); reduce speed loss; six big losses; total productive maintenance (TPM)

\section{Abstract}

The manufacturing industry, especially the automotive industry in Indonesia, is growing rapidly. A company's policy to win business competition requires great effectiveness and efficiency in company management. One of the policies taken at PT $X Y Z$ is to increase production capacity. This policy is implemented with the addition of machines and increased output on existing machines. Method used to measure machine performance in PT. XYZ is one of the Total Equipment Security (OEE) based on Total Productive Maintenance (TPM). From the calculation results, the percentage of Overall Value of Equipment Efficiency (OEE) in August 2019 is 70\%. The value obtained does not meet the standard value set at the result of the OEE value of $85 \%$. When viewed in the Pareto Diagram for the Reduce Speed Loss factor has the highest amount of time loss and the lowest cumulative frequency of the Big Six Losses which greatly affects the OEE value obtained. PT. XYZ must provide training to the operator 
on machine maintenance so that the performance of the press machine can be improved, perform die inspections and make related schedules in routine die inspections, make a special team of Inspectors to be able to perform periodic inspections, and make provisions on spare parts. Important

Keyword: overall equipment efficiency (OEE); reducing speed los; six big losses; total productivity maintenance (TPM)

\section{Pendahuluan}

Perkembangan perekonomian saat ini di perusahaan harus mampu bersaing dengan perusahaan lainnya. Manajemen perusahaan oleh karena itu perlu mengadakan penyesuaian, sehingga dapat mengikuti perkembangan dan melakukan perbaikan yang berkesinambungan. Adanya suatu penyesuaian dilakukan demi menjaga kualitas serta produktifitas perusahaan secara efektif dan efisien sehingga mampu bersaing dengan perusahaan. Perusahaan harus meningkatkan keunggulan kompetitif, karena hal ini sangat diperlukan dalam menghadapi persaingan usaha. Manajemen perusahaan dalam mencapai hal tersebut bertanggungjawab untuk menjaga, mempertahankan serta meningkatkan kualitas produknya agar lebih mampu bersaing di pasar. Perusahaan yang menjadikan kualitas sebagai alat strategi akan mempunyai keunggulan bersaing terhadap pesaingnya dalam menguasai pasar, karena tidak setiap perusahaan mampu menciptakan produk dengan kualitas yang baik.

Pemeliharaan merupakan suatu kegiatan perawatan menjaga kualitas dan efektifitas mesin agar mesin tersebut tidak cepat rusak atau untuk memperbaiki sampai pada kondisi yang dapat diterima. Pemeliharaan dapat dilakukan dengan menjaga fasilitas - fasilitas dan peralatan pabrik serta mengadakan perbaikan dan penyesuaian yang diperlukan agar tercapai suatu keadaan operasi produksi yang memuaskan dan tercapai. Pemeliharaan dilakukan agar proses produksi di suatu pabrik dapat berjalan lancar dan terjamin (Tampubolon, 2004).

Mesin produksi dapat dikatakan baik apabila dapat berfungsi dengan efektif dan efisien dalam menghasilkan output dari prosesnya. Setiap mesin juga mempunyai faktor umur yang akan berdampak terhadap kegunaan mesin. Makin tua umur mesin, maka semakin sering mengalami kerusakan jika tidak dirawat dengan baik. Kerusakan ini dapat menyebabkan kegiatan proses produksi terhambat, untuk itu dibutuhkan pengukuran kinerja mesin guna menghindari kerusakan supaya mesin tersebut dapat berproduksi secara efektif dan efisien. Metode yang digunakan untuk mengukur kinerja mesin salah satunya adalah Overall Equipment Effetiveness (OEE). OEE merupakan suatu metode pengukuran efektifitas penggunaan suatu mesin atau peralatan yang merupakan dasar dari Total Productive Maintenance (TPM). (Assauri, 2008).

Menjelaskan bahwa perawatan preventif dilakukan untuk menjaga keadaan peralatan sebelum peralatan itu menjadi rusak, pada dasarnya yang dilakukan untuk mencegah timbulnya kerusakan- kerusakan yang tak terduga dan menentukan keadaan yang dapat menyebabkan fasilitas produksi mengalami kerusakan pada waktu digunakan dalam proses produksi. Perawatan preventif ini sangat penting, karena kegunaannya 
sangat efektif didalam fasilitas - fasilitas produksi yang termasuk dalam golongan "critical unit" (Sulaeman, 2015)

Six big losses merupakan enam kerugian yang harus dihindari oleh setiap perusahaan untuk mengurangi tingkat efektifitas suatu mesin. Rendahnya produktivitas mesin/peralatan yang menimbulkan kerugian bagi perusahaan sering diakibatkan oleh penggunaan mesin/peralatan yang tidak efektif dan efisien. Kerugian dapat diselesaikan dengan menerapkan efektivitas peralatan secara keseluruhan, melakukan pengukuran OEE, melakukan TPM, dan juga mengidentifikasi kerugian produksi (Chikwendu \& Chima, 2018). Six big losses menurut (Alvira et al., 2015) dapat dikategorikan menjadi 3 kategori utama berdasarkan aspek kerugiannya yaitu downtime losses, speed losses, dan quality losses.

Hal ini dilakukan untuk mendapatkan output produksi yang maksimal serta mampu memenuhi target yang telah ditetapkan oleh perusahaan. Mesin produksi yang terpasang saat ini di PT. XYZ, Terdapat 3 mesin yaitu mesin Draw, Trim, Flange.

Latar belakang pemilihan mesin produksi tersebut sebagai objek pengamatan dalam tugas akhir ini adalah karena pada line produksi ini seringkali terjadi kerugian (losses) produksi, baik yang disebabkan oleh mesin dan peralatan produksi maupun operator dalam menjalankan proses produksi. Hal ini menyebabkan pencapaian output produksi khususnya pada mesin press, belum memenuhi target yang ditetapkan oleh perusahaan.

Downtime Mesin Press berdasarkan data diatas paling tinggi terjadi pada tanggal 28 agustus yaitu 6.621 detik. Paling rendah terjadi pada tanggal 02 agustus yaitu 2.204 detik. Hal ini oleh karnanya perlu dilakukan identifikasi untuk mengetahui tingkat performa mesin press pada PT. XYZ.

Tujuan dari penelitian ini berdasarkan latar belakang tersebut, maka permasalahan yang penulis rumuskan ialah: 1) Mengetahui nilai OEE (Overall Equipment Efectivness) proses produksi pada line produksi stamping di PT. XYZ selama 1 Agustus 2019 - 31 Agustus 2019. 2) Mengetahui Faktor apa saja yang mempengaruhi tinggi rendahnya nilai Overall Equipment Effectiveness dan Six Big Losses? 3) Memberikan usulan perbaikan (improvement) untuk membantu kelancaran proses produksi mesin press di PT.XYZ

\section{Metode Penelitian}

Penelitian yangakan dilakukan pada dasarnya dapat dibagi menjadi dua, yaitu penelitian kuantitatif dan kualitatif. Mesin pemeliharaan alat perlu diukur secara kuantitatif dengan pengukuran nilai OEE untuk mengetahui tingkat efisiensinya dan mencari six big losses nya serta rangking losses dalam pareto chart. Faktor lain seperti kehandalan teknisi, konsistensi penggunaan checklist dan SOP, penerapan 5S, serta beberapa pilar TPM yang perlu dinilai secara kualitatif dengan menggunakan pendekatan analisis fishbone diagram sebagai acuan dalam pengambilan keputusan.

Penelitian dilakukan untuk mendapatkan data yang diinginkan pada PT. XYZ yang merupakan perusahaan yang bergerak di bidang otomotif. Proses penelitian terhadap preventive maintenance pulser ini akan dilaksanakan dalam jangka waktu selama periode satu tahun (Rahmad et al., 2012). 
Jenis data yang diperoleh akan dikelompokkan menjadi dua bagian, yaitu data primer dan data sekunder :

1. Data Primer

Data primer merupakan data yang diperoleh melalui pengamatan lapangan langsung untuk melihat parameter-parameter dari proses pemeliharaan Mesin Press secara keseluruhan seperti downtime, cycle time, jumlah produksi, jumlah defect, jam kerja mesin, dan plannd downtime. Pengambilan data menggunakan wawancara juga digunakan, karena untuk melakukan pengambilan data terhadap beberapa karyawan yang terkait dengan proses maintenance, data dan informasi diolah kedalam (Almeanazel, 2010).

perhitungan nilai OEE dan kemudian akan diteliti beberapa Losses yang dihasilkan. Losses terbesar perlu dicari cause-effect unsur 5 M-nya (Man, Material, Method, Machine, Measurement) dan Enviroment untuk mencari solusi perbaikan.

2. Data Skunder

Data sekunder merupakan data yang diperoleh dari beberapa sumber studi literatur. Data sekunder digunakan sebagai refrensi dalam penelitian, yaitu :

a. Jurnal diakui secara nasional seperti JURNAL PASTI, maupun jurnal internasional yang diakui dan memiliki nomor ISSN.

b. Hasil penelitian sebelumnya, seperti jurnal ilmiah yang menggunakan metode Overall Equipment Effectiveness (OEE), Six Big Losses dan Total productive Maintenance (TPM)

Pengolahan data dilakukan dengan menggunakan metode Overall Equipment Effectiveness (OEE), Six Big Losses dan Total productive Maintenance (TPM) dengan tahap sebagai berikut :

a. Perhitungan nilai Overall Equipment Effectiveness (OEE).

b. Perhitungan nilai Six Big Losses.

c. Analisis hasil yang didapatkan dari perhitungan Availability, performance, Quality rate, dan Overall Equipment Effectiveness (OEE).

d. Analisis terjadinya faktor Six Big Losses.

e. Penarikan kesimpulan dan saran yang akan diajukan sebagai rekomendasi solusI untuk meningkatkan nilai Overall Equipment Effectiveness (OEE) pada mesin press.

\section{Hasil dan Pembahasan}

\section{Analisis Pencapaian Nilai Overall Equipment Effectiveness (OEE)}

Analisis Overall Equipment Effectiveness dilakukan untuk mengukur tingkat efektifitas masin press. Pencapaian OEE mesin press berdasarkan hasil dari perhitungan dan pengolahan data didapatkan bahwa rata-rata pencapaian OEE dari mesin press (Asgara \& Hartono, 2014).

Table perbandingan ketiga factor dan pencapain OEE dari mesin press dengan standar OEE Internasional : 
Tabel 1 Perbandingan pencapaian nilai OEE actual dengan nilai World Class Standard Factor World Class Standard Actual Value

\begin{tabular}{lll}
\hline Factor & $\begin{array}{l}\text { World Class } \\
\text { Standard }\end{array}$ & $\begin{array}{l}\text { Actual } \\
\text { Value }\end{array}$ \\
\hline Availability & $90 \%$ & $84 \%$ \\
\hline Performance & $95 \%$ & $77 \%$ \\
\hline Qualiy & $99 \%$ & $96 \%$ \\
\hline OEE & $85 \%$ & $62 \%$
\end{tabular}

Analisa hasil perhitungan Overal Equipment Effectiveness di PT. XYZ pada mesin Press. Perhitungan ini dilakukan untuk mengetahui tingkat keefektifas mesin dalam melaksanakan produksi. Perhitungan nilai Overall Equipment Effectiveness meliputi tiga rasio seperti Availability, Performance, dan Quality. Hasil nilai ketiga rasio tersebut dihitung berdasarkan data-data yang bersumber dari PT. XYZ

\section{Analisis Availability Rate}

Availibility merupakan suatu rasio dimana untuk mengetahui tingkat waktu yang tersedia pada mesin yang dimana availibility merupakan salah satu rasio untuk mengetahui nilai Overall Equipment Effectiveness (OEE). Berikut persentase availibility mesin Press dari

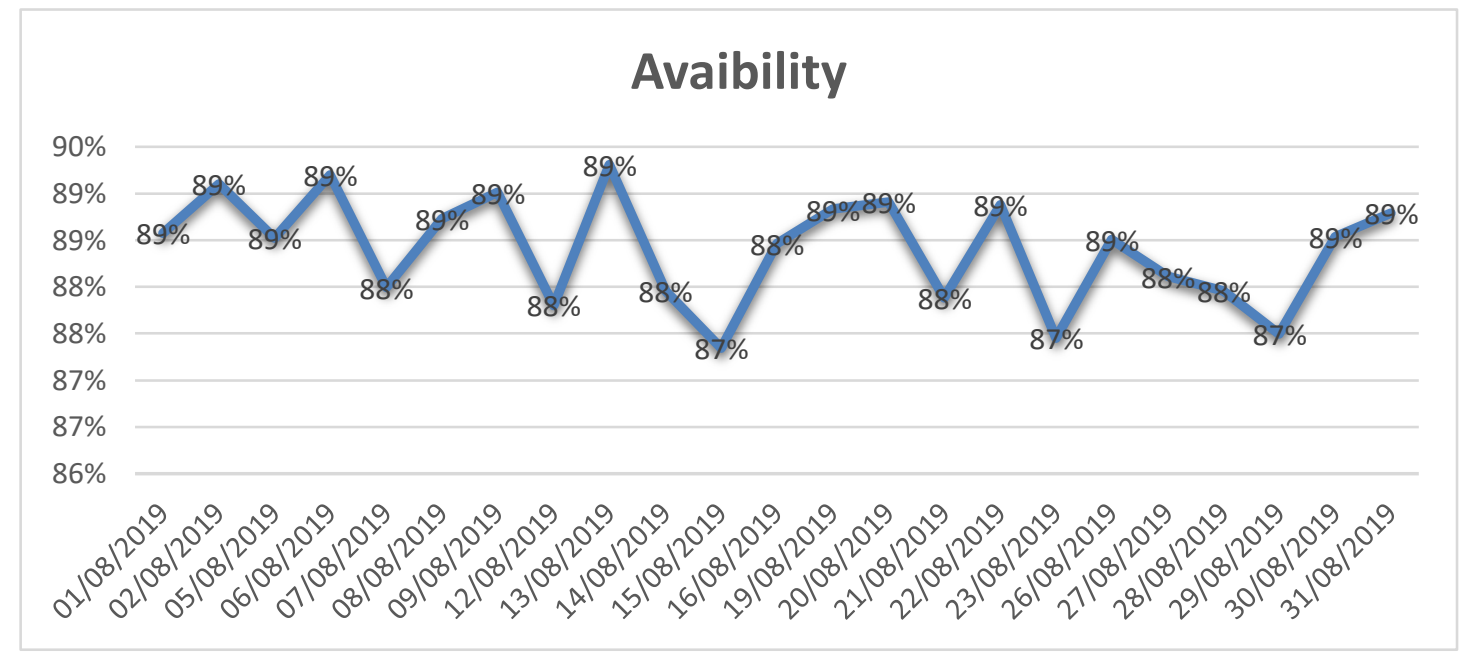

periode 1 - 30 Agustus 2019:

Gambar 1 Grafik Persentase Availibility Mesin Press

(Sumber: Data diolah, 2020)

Berdasarkan grafik diatas dapat diketahui bahwa terdapat presentase dengan nilai availibility terendah pada pada tanggal 15 agustus dengan hasil persentase sebesar $87 \% \%$ ini disebabkan karena tingginya downtime sebesar 4149 detik, sedangkan dengan persentase tertinggi di dapatkan pada tanggal 13 agustus dengan hasil nilai sebesar $89 \%$ hal ini disebabkan karena rendahnya downtime dengan sebesar 2649 detik. Rata - rata nilai availibility keseluruhan periode 1 - 31 agustus 2019 sebesar $88 \%$. 
Menurut Japan Institute of Plant Maintenance (JIPM) standar nilai availibility kelas dunia sebesar $90 \%$. Dalam hal ini nilai availibility perusahaan sudah mencapai nilai standar availibility kelas dunia (Limantoro, 2013).

\section{Analisis Performance Rate}

Performance merupakan suatu rasio yang menggambarkan suatu kemampuan mesin dalam menghasilkan suatu produk. Performance rate ini merupakan rate yang menentukan nilai OEE. Berikut persentase perhitungan performance rate:

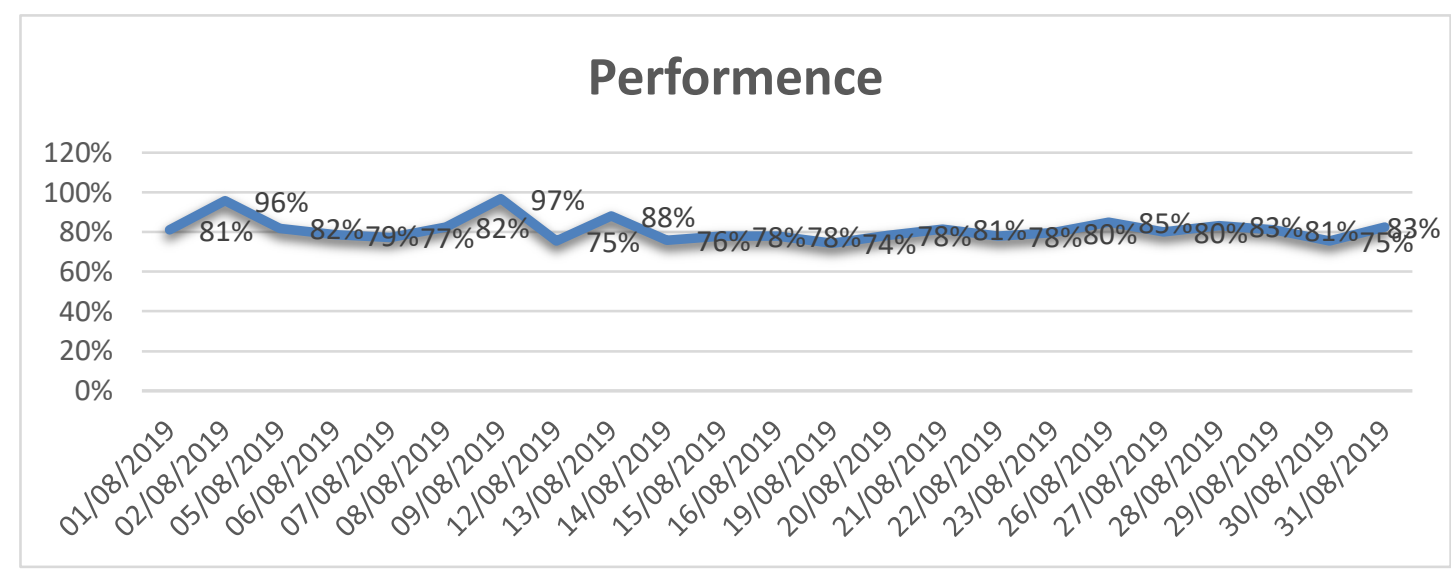

Gambar 2 Persentase Performance Rate Mesin Press

(Sumber: Data diolah, 2020)

Pada grafik diatas menunjukan bahwa nilai performance mesin dengan nilai tertinggi pada tanggal 9 agustus dengan nilai sebesar 97\% disebabkan karena dengan jumlah waktu pada saat operasi mesin dengan jumlah yang diproduksi dua kali lebih banyak dibandingkan bulan yang lainnya, sedangkan dengan tingkat persentase performance terendah pada tanggal 19 dengan nilai sebesar $74 \%$ disebabkan karena nilai waktu mesin memiliki waktu dengan jumlah yang besar sebesar 28.543 detik dan tingginya produksi sebesar 3.140 pcs.

Menurut Japan Institute of Plant Maintenance (JIPM) standar untuk nilai performance rate kelas dunia sebesar $95 \%$ sedangkan nilai performance rate perusahaan sebesar $81 \%$. Hal ini di karenakan kurangnya penerapan total productive maintenance yang menyebabkan kemampuan mesin dalam operasi rendah tetapi nilai performance perusahaan tidak terlampau jauh dengan standar performance kelas dunia (Chikwendu \& Chima, 2018). 


\section{Analisis Quality Rate}

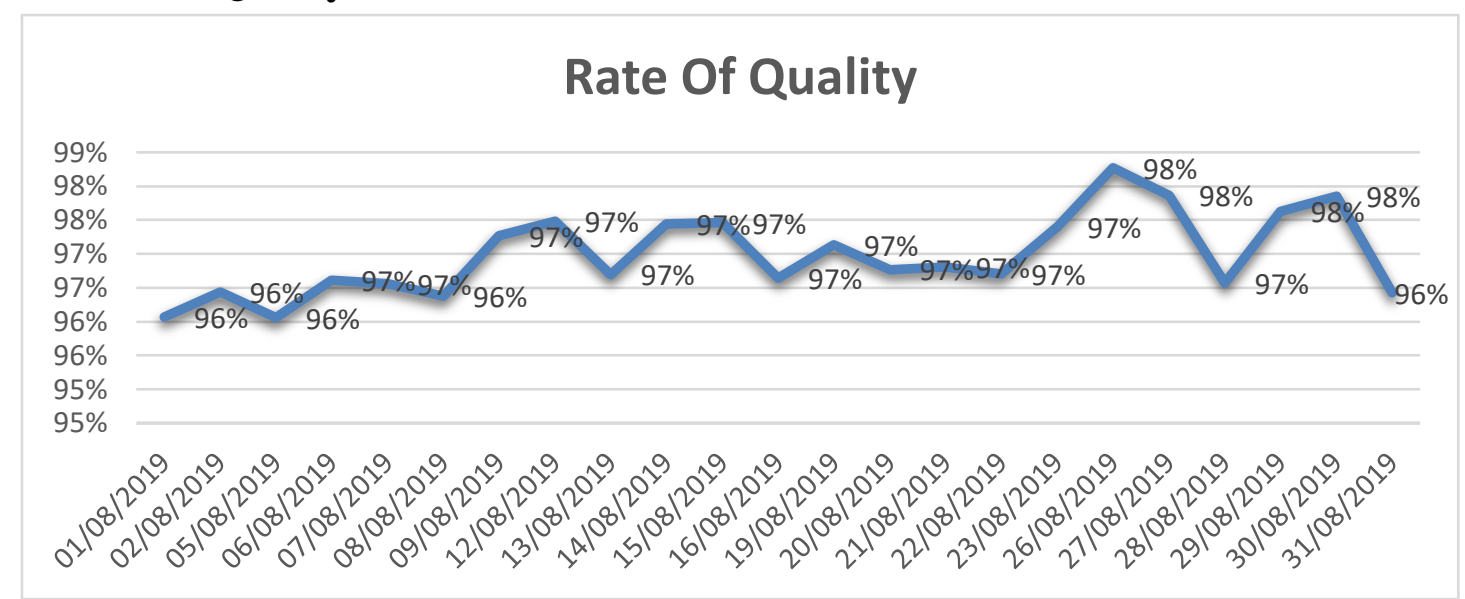

Gambar 3 Persentase Quality Rate Mesin Press

(Sumber: Data diolah, 2020)

Quality merupakan suatu rasio yang menggambarkan suatu mesin untuk menghasilkan suatu produk yang berstandar. Variabel dalam quality yaitu jumlah produksi dan cacat produk. Berikut persentase perhitungan quality rate mesin press :

Berdasarkan grafik presentase di atas bahwa quality rate tertinggi di tanggal 27 agustus dengan sebesar $98 \%$ sedangkan nilai quality rate terendah di tanggal 2 agustus dengan nilai $96 \%$ dikarenakan operator kurangnya waktu dalam pengecekan material dari ketetapan standar perusahaan dan nilai defect dengan jumlah terbanyak dengan jumlah 156 pcs. Rata - rata keseluruhan nilai quality rate sebesar 97\% (Dewi, 2012).

Menurut Japan Institute of Plant Maintenance (JIPM) untuk standar nilai quality rate kelas dunia sebesar $99 \%$ sedangkan nilai quality rate perusahaan masih dibawah nilai standar kelas dunia. Namun nilai selisih antara nilai perusahaan dengan standar kelas dunia tidak jauh hanya sebesar 2\% (Wakjira \& Singh, 2012).

\section{Analisis Nilai Overall Equipment Effectiveness (OEE)}

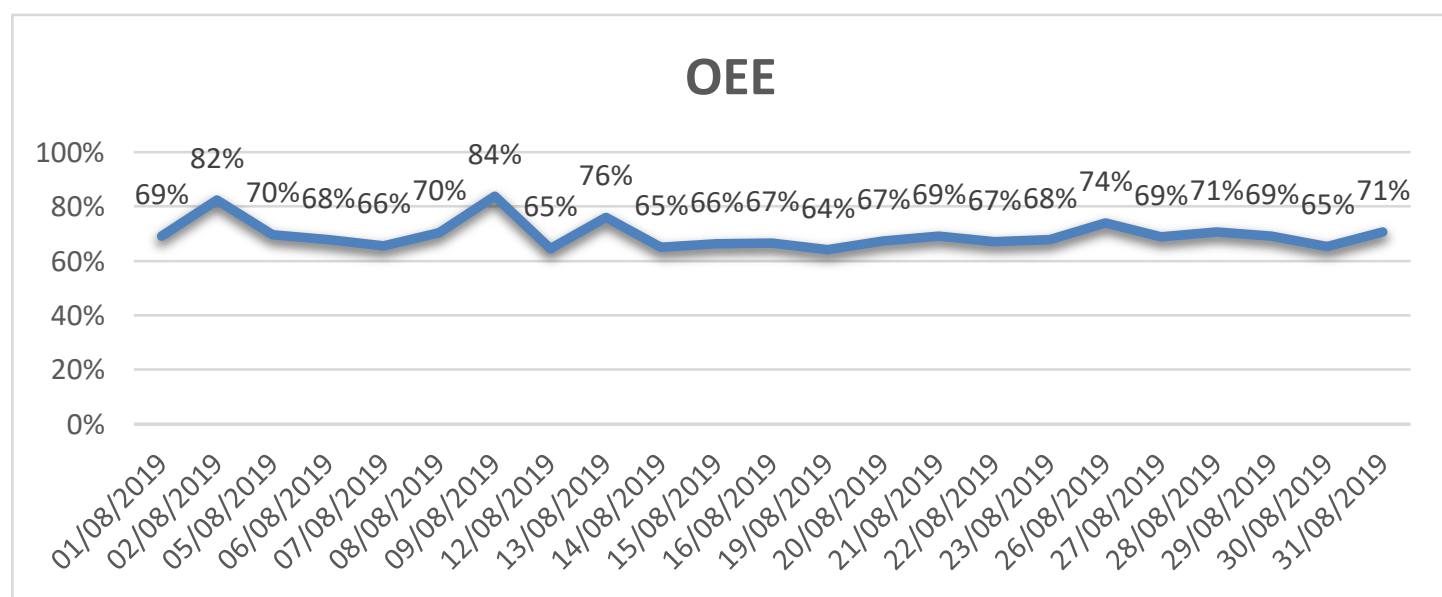

Gambar 4 Presentase Grafik OEE Mesin Press

(Sumber: Data diolah, 2020)

Berdasarkan grafik di atas nilai OEE dengan persentase tertinggi yaitu pada tanggal 9 agustus dengan nilai sebesar $84 \%$ disebabkan karena jumlah produk yang 
dihasilkan banyak dan tingginya waktu produksi, sedangkan nilai OEE terendah pada tangal 19 agustus dengan nilai 64\% disebabkan karena rendahnya nilai performa mesin. Untuk rata - rata nilai OEE mesin press periode 1 - 31 agustus 2019 sebesar 70\%.

Menurut Japan Institute of Plant Maintenance (JIPM) standar kelas dunia nilai OEE sebesar $85 \%$, sedangkan nilai OEE perusahaan $70 \%$ maka nilai tersebut belum mencapai nilai standar kelas dunia. Diperlukannya perbaikan mesin lebih lanjut agar nilai OEE suatu perusahaan mencapai nilai standar kelas dunia (Pandey et al., 2019).

\section{Analisis Hasil Perhitungan Six Big Losses}

Analisa hasil perhitungan Six Big Losses ini ialah untuk menganalisa masalah utama faktor - faktor Six Big Losses yang mempengaruhi hasil perhitungan Overal Equipment Effectiveness yang telah di dapat. Six Big Losses terdiri dari Equipment Failure loss, Setup \& Adjustment loss, Idle \& Minor Stoppage Loss, Reduce Speed Loss, Deffect Loss, Reduce Yield Loss. Analisa ini dilakukan berdasarkan presentase kumulatif dari perhitungan total time loss pada masing - masing faktor Six Big Losses.

Tabel 2 Total Timeloss Six Big Losses

\begin{tabular}{llllll}
\hline No & Six Big Losses & $\begin{array}{l}\text { Total Time } \\
\text { Losses }\end{array}$ & $\begin{array}{l}\text { Persentase } \\
(\%)\end{array}$ & $\begin{array}{l}\text { Persentase } \\
\text { Kumulatif }\end{array}$ & OEE \\
\hline 1 & Equipment Failure Losses & 77804 & $28.9 \%$ & $29 \%$ & Availability \\
\hline 2 & Setup \& Adjustment Losses & 74047 & $27.5 \%$ & $56 \%$ \\
\hline 3 & Idling and Minor Stoppages & 0 & $0.0 \%$ & $56 \%$ & \multirow{2}{*}{ Performance } \\
\hline 4 & Reduce Speed Losses & 112902 & $42.0 \%$ & $98 \%$ & \multirow{2}{*}{ Quality } \\
\hline 5 & Yield/Scrap Losses & 1656 & $0.6 \%$ & $99 \%$ & $100 \%$ \\
\hline 6 & Defect Losses & 2463 & $0.9 \%$ & $100 \%$ & \\
\hline TOTAL & 268871 & & & \\
\hline
\end{tabular}

(Sumber: Data diolah, 2020)

Analisa Reduce Speed Loss ialah kerugian yang diakibatkan menurunnya standar kecepatan pada peralatan dan mesin. Pada Diagram Pareto terlihat untuk Reduce Speed Loss hasil perhitungannya ialah Total Time Loss sebesar 112.902 detik dan persentase berkisar $42 \%$. Dari masing - masing faktor Six Big Losses hasil perhitungan time lose dan persentase tertinggi terdapat pada Reduce Speed Loss.

\section{Kesimpulan}

Setelah pengolahan data dan menganasilsa mesin Press di PT.XYZ dengan menggunakan metode Overall Equipment Effectivenss ( OEE ), pada bulan Agustus 2019, maka dapat ditarik kesimpulan sebagai berikut : 1) Diperoleh nilai hasil presentase rasio Availability berkisar diantara $87 \%-89 \%$, sedangkan untuk nilai presentase nilai rasio Performance berkisar diantara 74\% - 97\% dan untuk nilai presentase rasio Quality berkisar diantara 96\% - 98\%. Lalu diperoleh presentase dari nilai Overall Equipment Effectiveness berkisar diantara 64\% - 84\%. Dengan rata-rata nilai OEE pada bulan Agustus 2019 yaitu sebesar 70\%. 2) Faktor yang paling berpengaruh pada rendahnya efektivitas mesin Press dengan menggunakan analisa metode Overall Equipment 
Effectiveness yaitu faktor Reduce Speed Loss yaitu menurunya kecepatan mesin produksi yang diakibatkan oleh kelalaian operator saat bekerja, die tidak senter, dan menunggu perbaikan mesin yang rusak. 3) Usulan perbaikan memberikan pelatihan secara detail terhadap operator pada saat sebelum terjun kelapangan, membuat penjadwalan terkait pemeriksaan operator secara berkala, melalukan inpeksi terhadap bahan baku agar menguragi kedeffectan terhadap ptoduk, pergantian part sesuai dengan prosedur pihak manufactur, Melalukan inpeksi terhadap die dan membuat penjadwalan terkait dalam pemeriksaan die secara rutin, Membuat tim Inspektor khusus agar dapat melakukan inspeksi secara rutin, dan melalukan penyetokan terhadap suku cadang yang krusial. 


\section{Bibliografi}

Almeanazel, O. T. R. (2010). Total productive maintenance review and overall equipment effectiveness measurement. Jordan Journal of Mechanical and Industrial Engineering, 4(4).

Alvira, D., Helianty, Y., \& Prassetiyo, H. (2015). Usulan Peningkatan Overall Equipment Effectiveness ( Oee ) Pada Mesin Tapping Manual Dengan Meminimumkan Six Big Losses. Jurnal Itenas Bandung, 03(03), 240-251.

Asgara, B. Y., \& Hartono, G. (2014). Analisis Efektifitas Mesin Overhead Crane Dengan Metode Overall Equipment Effectiveness (Oee) Di Pt. Btu, Divisi Boarding Bridge. Inasea, 15(1), 62-70.

Assauri, S. (2008). Manajemen Produksi dan Operasi edisi revisi. Jakarta: Lembaga Penerbit Fakultas Ekonomi Universitas Indonesia.

Chikwendu, O. C., \& Chima, A. S. (2018). Overall Equipment Effectiveness and the Six Big Losses in Total Productive Maintenance Available online www.jsaer.com Journal of Scientific and Engineering Research , 2018 , 5 ( 4 ): 156-164 Overall Equipment Effectiveness and the Six Big Losses in Total. Journal of Scientific and Engineering Research, 5(4), 156-164.

Dewi, S. K. (2012). Minimasi defect produk dengan konsep six sigma. Jurnal Teknik Industri, 13(1), 43-50.

Limantoro, D. (2013). Total Productive Maintenance di PT. X. Jurnal Titra, 1(1), 13-20.

Pandey, A., Malviya, S., \& Jain, S. (2019). Implemented the Overall Equipment Effectiveness (OEE) by the techniques of Total Productive Maintenance (TPM) in MSE's-A case study.

Rahmad, R., Pratikto, P., \& Wahyudi, S. (2012). Penerapan Overall Equipment Effectiveness (Oee) Dalam Implementasi Total Productive Maintenance (TPM)(Studi Kasus di Pabrik Gula PT."Y”.). Rekayasa Mesin, 3(3), 431-437.

Sulaeman. (2015). Perbaikan Penurunan Daya Mampu Dan Pemeliharaan Mesin Diesel Kapasitas $1000 \mathrm{Kw}$ Di Pltd Koto Lolo (Vol. 5, Issue 2).

Tampubolon, M. P. (2004). Manajemen Operasional. In Ghalia Indonesia, Jakarta (Issue 2005).

Wakjira, M. W., \& Singh, A. P. (2012). Total productive maintenance: A case study in manufacturing industry. Global Journal of Research in Engineering, 12(1-G). 